\title{
A CLINICAL STUDY ON LIMITED DORSAL APPROACH FOR OPEN REDUCTION OF KAPLAN'S DISLOCATION (DORSAL DISLOCATION OF METACARPOPHALANGEAL JOINT OF INDEX FINGER)
}

\author{
Sathis Chandran $P^{1}$
}

${ }^{1}$ Associate Professor, Department of Orthopaedics, Kannur Medical College, Anjarakandy, Kannur, Kerala.

\section{ABSTRACT}

\section{BACKGROUND}

Dislocation of Metacarpophalangeal (MCP) joint of index linger is an uncommon injury encountered in Orthopaedic practice. Closed reduction is commonly attempted and in cases of irreducibility open reduction by volar approach is used as described by Kaplan. In the present study, a dorsal approach is used in a series of patients which has many advantages.

Aim- To describe and use limited dorsal approach in the management of irreducible dorsal dislocation of Metacarpophalangeal joint.

\section{MATERIALS AND METHODS}

45 patients between the ages of 8 and 45 with irreducible dorsal dislocation of Metacarpophalangeal joint were included for the study and a minimal dorsal approach performed in reducing the dislocation.

\section{RESULTS}

30 patients had a good recovery of joint function and incidence of joint stiffness noted in 5 patients. 2 patients lost for followup and two patients developed Osteonecrosis of the metacarpal head. 2 patients developed premature closure of the physis.

\section{CONCLUSION}

Dorsal dislocation of Metacarpophalangeal joint of index finger (Kaplan's dislocation) which is irreducible by closed manipulation is best approached dorsally and limited dorsal approach by simple stab incision is enough in most of the cases.

\section{KEYWORDS}

Joint, Metacarpophalangeal, Reduction, Irreducible Dislocations and Kaplan's Dislocation.

HOW TO CITE THIS ARTICLE: Chandran SP. A clinical study on limited dorsal approach for open reduction of Kaplan's dislocation (dorsal dislocation of metacarpophalangeal joint of index finger). J. Evolution Med. Dent. Sci. 2017;6(25):2087-2091, D0I: $10.14260 /$ Jemds/2017/454

\section{BACKGROUND \\ Dorsal dislocation of Metacarpophalangeal joint of index linger is an uncommon injury. Campbell's Operative Orthopaedics, $3^{\text {rd }}$ edition published in 1956 does not mention about this dislocation. ${ }^{1}$ It was Kaplan who gave the accurate pathological anatomy of this injury in 1957 and so the injury may also be called Kaplan's dislocation and this is described in the later editions of Campbell's Operative Orthopaedics. ${ }^{2}$ He advocated a volar approach for the open reduction of this dislocation if closed manipulation fails and this is the standard approach used for this rare injury. Later in 1975, Becton et al $^{3}$ advocated a dorsal approach for open reduction of this dislocation. Bohart et $\mathrm{al}^{4}$ in 1982 has also described dorsal approach for open reduction.}

\section{Purpose of the Study}

To describe limited dorsal approach to open reduction for irreducible Metacarpophalangeal joint Dislocation and its advantages over classical Volar approach.

Financial or Other, Competing Interest: None.

Submission 03-02-2016, Peer Review 16-03-2017,

Acceptance 22-03-2017, Published 27-03-2017.

Corresponding Author:

Dr. Sathis Chandran P,

Associate Professor

Department of Orthopaedics,

Kannur Medical College, Anjarakandy,

Kannur, Kerala.

E-mail: sathisv@gmail.com

DOI: $10.14260 /$ jemds $/ 2017 / 454$

(c) $($ ) $(5)$

\begin{abstract}
MATERIALS AND METHODS
45 patients with irreducible Dislocation of Metacarpophalangeal joint attending the teaching Hospital attached to Kannur Medical College, Anjarakandy, Kannur, Kerala were included in the present study. The study period was between March 2010 and Feb 2016. An ethical committee clearance certificate was obtained from the Institute. Due consent from the patients were obtained. Irreducible dislocation was defined as a dislocation which is not amenable for closed reduction for more than 3 attempts. Demographic data and history and nature of injury were recorded.
\end{abstract}

\section{Inclusion Criteria}

1. All the patients aged between 8 and 45 years with dislocation of Metacarpophalangeal joint not reducible with closed manipulation were included. 2. Patients with history of striking of the outstretched index finger against a resistant object usually in a fall on the hand were included. 3 . Dislocations where the base of the proximal phalanx is displaced over the dorsum of the metacarpal head. 4. Patients coming with dislocation 24 hours or more are included.

\section{Exclusion Criteria}

Cases of Metacarpophalangeal joint dislocation where closed reduction without general anaesthesia was successful were excluded. Children below 8 years and above 45 were excluded.

All the patients were subjected to X-ray examination of the hand to assess the bony injuries and joint status. The operative technique used in this study is under general anaesthesia; an attempt is made to reduce the dislocation by closed manipulation. The metacarpophalangeal joint is hyperextended and tried to push the fibrocartilaginous plate 
volar wards by the proximal phalanx. If the closed reduction fails, using a triangular knife (No. 11) a stab incision is made on the medial side of the extensor tendon down to the bone cutting the joint capsule and fibro-cartilaginous plate while the assistant steadies the hand and tries to flex the Metacarpophalangeal joint attempting reduction of dislocation. The wound is closed in layers with external splinting for 3 weeks. All the patients were followed up for 3 years. All the data was analysed with standard statistical methods.

\section{RESULTS}

Among the 45 patients selected for open reduction of irreducible dislocation of Metacarpophalangeal joint, there were 36 male and 9 female patients. The patients were aged between 8 and 45 years. The mean age was 29.26 \pm 1.4 (Table 1). 32 patients attended the OPD in less than 24 hours and 13 patients after more than 24 hours of injury. 13 patients were found to have associated fractures of small bones of the hand. Simple dislocation was found in 4 and the remaining 41 were complex dislocations (Table 1).

\begin{tabular}{|c|c|c|c|c|c|}
\hline Age Groups & Male- 36 & Female- 09 & $\begin{array}{c}\text { Associated } \\
\text { Fractures- 13 }\end{array}$ & $\begin{array}{c}\text { Simple } \\
\text { Dislocation- 04 }\end{array}$ & $\begin{array}{c}\text { Complex } \\
\text { Dislocation- 41 }\end{array}$ \\
\hline 8 to 13 & 06 & 01 & 01 & 00 & 07 \\
\hline 14 to 29 & 17 & 04 & 05 & 02 & 19 \\
\hline 30 to 45 & 13 & 04 & 07 & 02 & 15 \\
\hline \multicolumn{7}{|r|}{ Table 1. Showing the Sex Distribution and Types of Dislocations (n=45) } \\
\hline
\end{tabular}

X-Ray examination and intra-operative findings showed 16 patients had volar plate interposed within MCP joint, 10 had parallel alignment of MCP volar skin dimpling, 4 patients had sesamoid seen within the joint, 10 patients showed MC trapped in different volar palm structures, and 5 patients with superficial transverse ligament (Table 2).

\begin{tabular}{|l|c|c|}
\hline \multicolumn{1}{|c|}{ Observation } & Male- 36 & Female- 09 \\
\hline $\begin{array}{l}\text { Volar plate interposed within } \\
\text { MCP joint }\end{array}$ & 16 & 00 \\
\hline $\begin{array}{l}\text { Parallel alignment of MCP, volar } \\
\text { skin dimpling }\end{array}$ & 08 & 02 \\
\hline Sesamoid seen within the joint & 03 & 01 \\
\hline $\begin{array}{l}\text { MC head trapped in volar palm } \\
\text { structures: 10 }\end{array}$ & & \\
\hline I. FDP & 02 & 01 \\
\hline II. Lumbrical & 02 & 02 \\
\hline III. Natatory & 02 & 01 \\
\hline $\begin{array}{l}\text { Superficial transverse MC } \\
\text { ligament }\end{array}$ & 03 & 02 \\
\hline $\begin{array}{l}\text { Table 2. Showing the Final Clinical findings after X-ray } \\
\text { and Intra-operative Examination (n=45) }\end{array}$ \\
\hline \multicolumn{2}{|c|}{}
\end{tabular}

The final results showed Good joint Mobility without stiffness in 30 patients, stiffness of the joint in 07 patients, arthritis in 03 patients, Osteonecrosis of the metacarpal head in 02 patients and premature closure of the physis in 03 patients. The overall efficiency of the surgical procedure was found to be $66.66 \%$.

\begin{tabular}{|c|c|c|}
\hline Post-Operative Results & Male-36 & Females-09 \\
\hline $\begin{array}{c}\text { Good Joint Mobility without } \\
\text { stiffness-30 }\end{array}$ & 24 & 06 \\
\hline Stiffness-07 & 07 & 00 \\
\hline Arthritis-03 & 02 & 01 \\
\hline $\begin{array}{c}\text { Osteonecrosis of the } \\
\text { metacarpal head-02 }\end{array}$ & 01 & 01 \\
\hline $\begin{array}{c}\text { Premature closure of the physis- } \\
\text { 03 }\end{array}$ & 02 & 01 \\
\hline $\begin{array}{c}\text { Table 3. Showing the Final Results of Dorsal Approach for } \\
\text { MCP Dislocation (n=45) }\end{array}$ \\
\hline
\end{tabular}

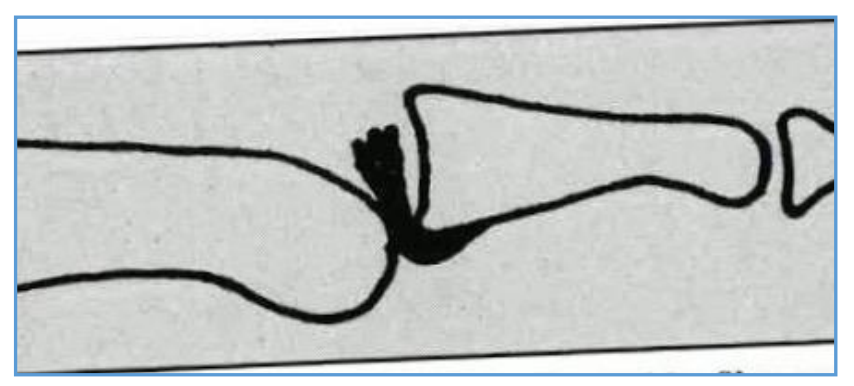

Figure 1. Showing the Fibrocartilaginous Plate of the Joint Displaced over the Head of the Metacarpal, Landing on the Dorsum of this Bone, where it becomes wedged between the Base of the Proximal Phalanx and the Head

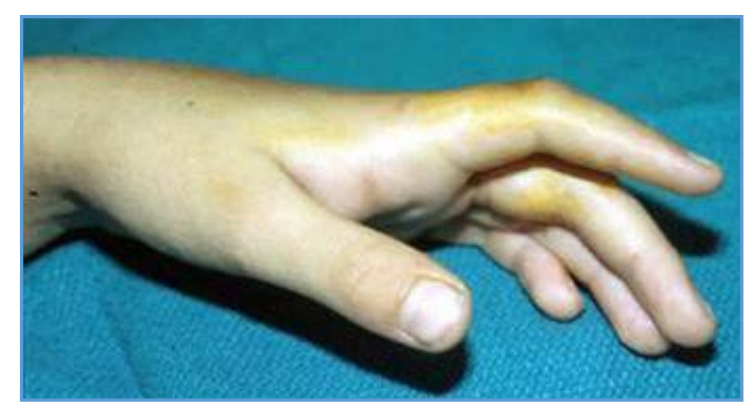

Figure 2. Showing Clinical Photograph of Metacarpophalangeal Joint Left Index Finger Dislocation 


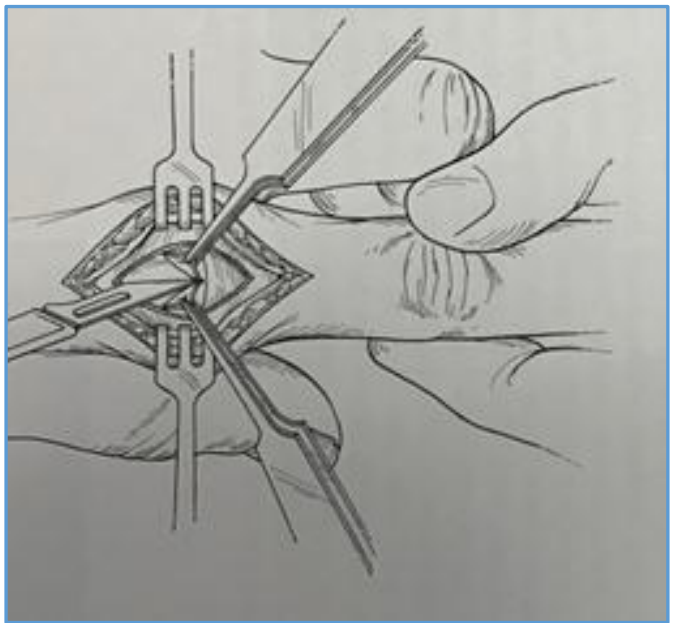

Figure 3: Showing Schematic Picture of Dorsal Incision and Approach

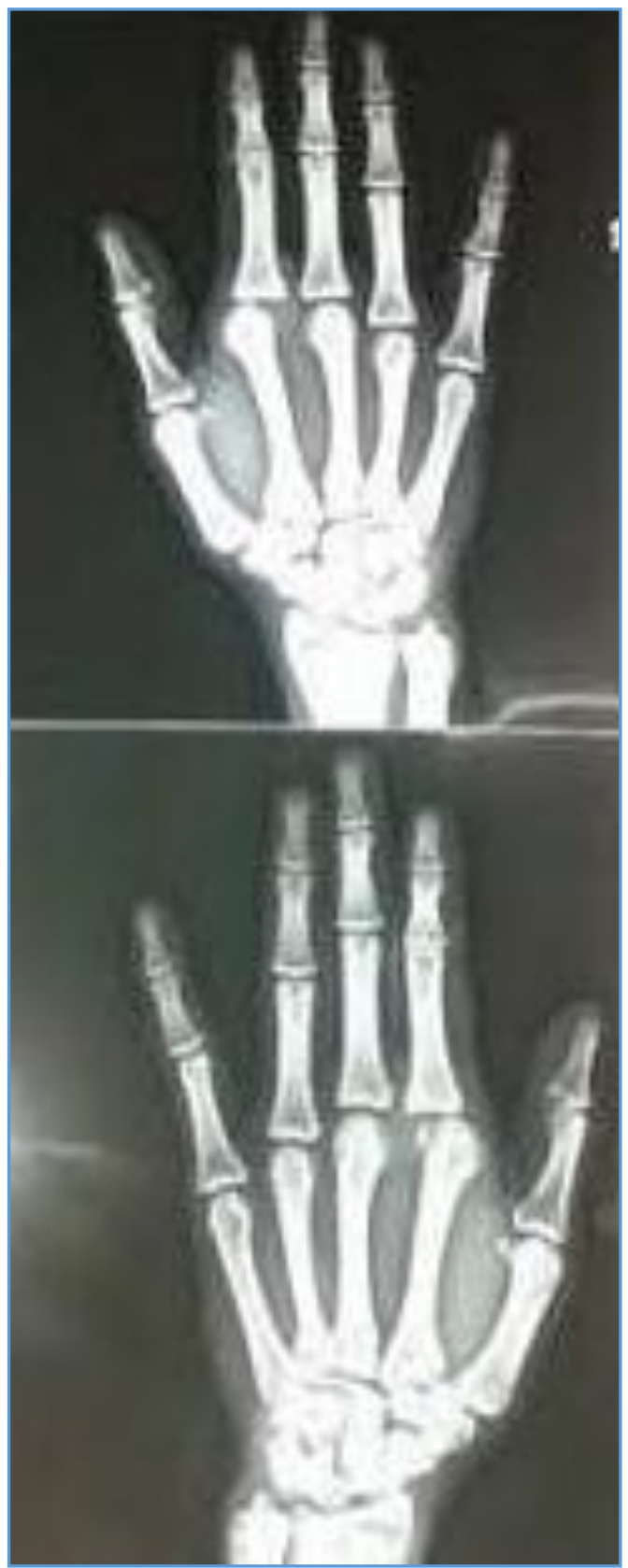

Figure 4. Showing the X-ray Hand with Dorsal Dislocation of Right Metacarpophalangeal Joint

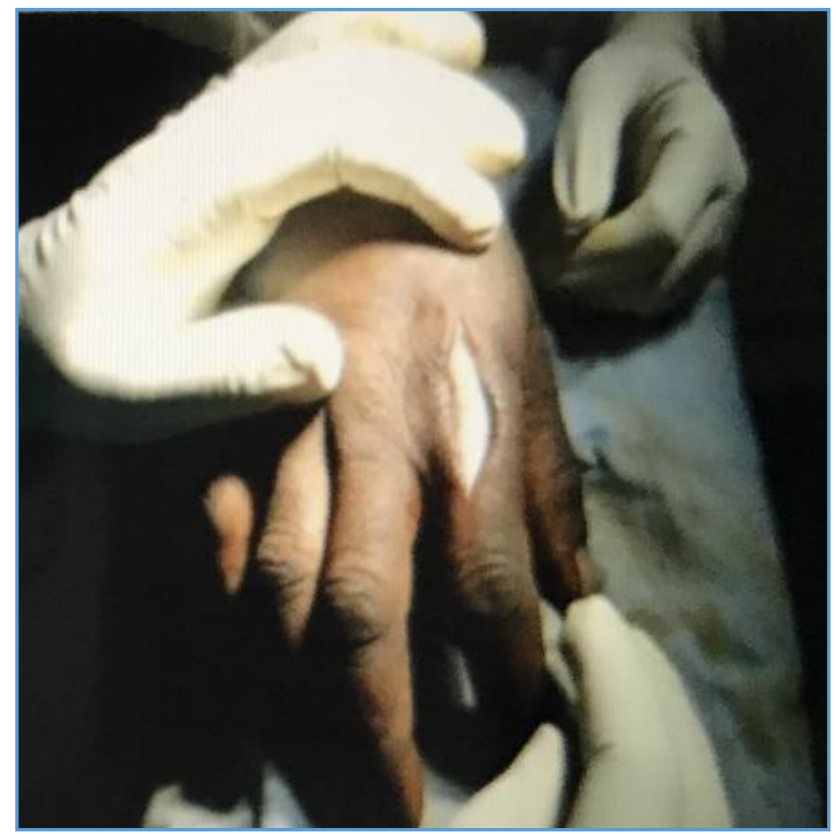

Figure 5. Showing the Incision on the Dorsal Aspect of Right Metacarpophalangeal Joint

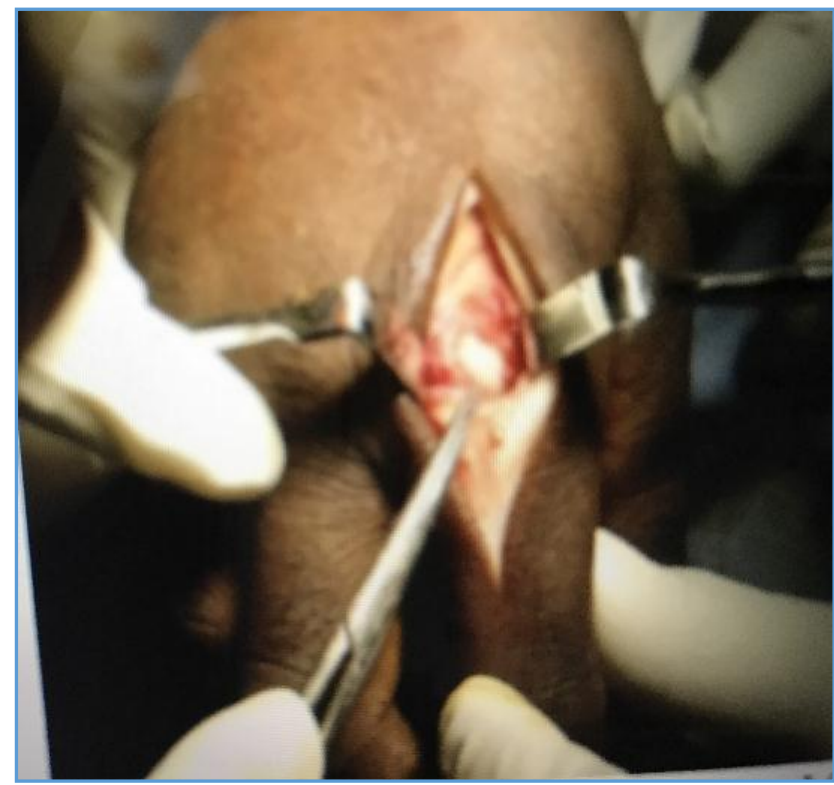

Figure 6. Showing the Dorsal Approach and Exploration of the Right Metacarpophalangeal Joint

\section{DISCUSSION}

Dislocation of Metacarpophalangeal joint of the index finger is an uncommon entity described by Kaplan and even today is known by his name. ${ }^{2}$ The pathological anatomy and standard operative procedure are well described by Kaplan. The fibrocartilaginous plate breaks away in the region of its weakest attachment, at the neck of the volar aspect of the second metacarpal; and the flexor tendons and the vaginal ligament and the pre-tendinous band or the mid-palmar fascia, which adheres to the vaginal ligament, are violently displaced to the ulnar side of the metacarpal head. Following this, the fibrocartilaginous plate of the joint is displaced over the head of the metacarpal, landing on the dorsum of this bone, where it becomes wedged between the base of the proximal phalanx and the head. The lateral collateral ligaments, which are now abnormally displaced, lock the phalanx in the abnormal 
position typical to this dislocation ${ }^{3}$ (Fig 1\& 2). At the same time, the two groups of transverse fibres of the palmar fascia hold the head of the metacarpal, the distal group (the Natatory ligament, which moves with the phalanx) applying pressure to the dorsum of the metacarpal head, while the proximal group (the superficial transverse ligament, which extends across the volar aspect of the metacarpal neck) applies pressure to the volar aspect. Thus, the dislocated metacarpal head lies between the natatory ligament and the superficial transverse ligament of the palmar fascia. The flexor tendons are on one side and the lumbrical muscle on the other. ${ }^{4}$ When the dislocation is incomplete, reduction by manipulation is easy. When it is complete, open reduction is often required. The major obstruction preventing reduction of the Metacarpophalangeal joint is the displaced volar fibrocartilaginous plate lying dorsal to the metacarpal head. 5 MCP is described as Simple and Complex Dislocations; Simple - reducible with closed reduction, and Complex - requires operative reduction, usually due to trapped Volar Plate. ${ }^{6}$ Sometimes, however, manipulation alone is successful. When the joint is hyperextended, the articular surface of the proximal phalanx is forced firmly against the metacarpal neck, and while this force is maintained, the joint is flexed. Sometimes this manoeuvre will trap the displaced fibrocartilaginous plate and carry it to its normal position anterior to the metacarpal head.7 The following is Kaplan's technique for open reduction: In open reduction, the incision is started in the thenar crease of the hand at the radial base of the index finger and is continued into the proximal crease of the hand. To reduce the dislocation following exposure, it is necessary to divide all the constricting bands. ${ }^{8}$ The first incision is made to free the constriction of the cartilaginous plate. This incision is placed parallel and radial to the vaginal ligament and extends from the free edge of the torn ligament to the junction of the periosteum with the proximal phalanx. The incision must penetrate the entire thickness of the plate. Division of the plate alone is not sufficient, however. The transverse fibres of the taut natatory ligament must also be completely divided, and following this, another longitudinal incision should be made through the transverse fibres of the superficial transverse metacarpal ligament. This third incision, which should extend to the ulnar side of the first lumbrical muscle, releases the constriction below the metacarpal head. This third incision "frees the base of the proximal phalanx, which then returns to its normal place over the metacarpal head. This, in turn, permits the immediate replacement of the second metacarpal head in line with the other metacarpal heads, following which the flexor tendons, the vaginal ligament, and the nerves and vessels are restored to their normal positions. ${ }^{9}$ The wound is then closed in the accepted manner, and the finger is immobilised in functional position for about one week. In the dorsal approach described by Becton et $\mathrm{al}^{3} 4 \mathrm{~cm}$ midline incision is made cutting the extensor tendon and joint capsule and then the fibrocartilaginous plate is incised longitudinally. The finger is flexed at the Metacarpophalangeal joint achieving reduction.

The Operative technique used in this study is under general anaesthesia an attempt is made to reduce the dislocation by closed manipulation. The Metacarpophalangeal joint is hyperextended and tried to push the fibrocartilaginous plate volar wards by the proximal phalanx. If the closed reduction fails, using a triangular knife number 11 blade, a stab incision is made on the medial side of the extensor tendon down to the bone cuffing, the joint capsule and fibrocartilaginous plate while the assistant steadies the hand and tries to flex the Metacarpophalangeal joint attempting reduction of dislocation. Sudden reduction of dislocation is achieved in most of the cases ( 9 cases). If this attempt fails to achieve reduction ( 3 cases), the stab incision is extended to make a $2 \mathrm{~cm}$ long incision. Extensor tendon is refracted radially, joint capsule and fibrocartilaginous plate is cut longitudinally and then reduction is achieved by manipulation. Postoperatively a plaster of Paris splint is given to immobilise the Metacarpophalangeal joint in $90^{\circ}$ flexion for about 10 days. Dorsal dislocation of Metacarpophalangeal is best approached through dorsal aspect. Reported complications include stiffness, arthritis, osteonecrosis of the metacarpal head, and even premature closure of the physis.10 In some cases, it is even recommended to do a dual anterior and a dorsal approach if the volar plate is not getting released easily. ${ }^{11,12,13}$ Advantages are: 1 . Dorsal approach gives better and fuller exposure of fibrocartilaginous plate which is the blocking structure preventing closed reduction. 2. Vital structures are less likely to be injured by dorsal approach like digital nerves, vessels and flexor tendon. Only structure to be protected is extensor tendon. 3. Dorsal approach is technically easier and simpler than volar approach described by Kaplan which needs a third incision. 4. In most cases, a simple dorsal stab incision (Limited Dorsal approach) is enough to achieve the reduction. 5. It is easier to treat associated fracture of the metacarpal head through dorsal approach because this fracture is usually on the dorsal aspect of the metacarpal head. If it is very small fragment, it may be excised. Otherwise, it may be fixed using a Kirschner wire (There were three cases in this series with metacarpal head fracture, all were reduced to anatomical position on reduction of dislocation). Volar approach carries a high risk of injury to the digital nerves and vessels but provides direct visualisation of the volar plate being released as advised initially by Kaplan. ${ }^{14}$ It is very easy to miss out on associated injuries especially when volar approach is used for open reduction. 15 The complex dislocations of MCP joint can be managed with dorsal as well as volar approach. The dorsal approach has advantages over the other as discussed above. Though, further clinical evaluation is to be done to assess the effectiveness of both methods.

None of the patients in this study had recurrence of dislocation or post-operative stiffness in the joint.

\section{CONCLUSION}

Dorsal dislocation of Metacarpophalangeal joint of index finger (Kaplan's dislocation), which is irreducible by closed manipulation is best approached dorsally and limited dorsal approach by simple stab incision is enough in most of the cases.

\section{REFERENCES}

[1] Brotzman BS, Manske RC. Campbell's operative orthopaedics. 3rd edn. Mosby Publishers 2011:438- 46.

[2] Willis C, Crenshaw AH, Edmonson, et al. Campbell's operative orthopaedics. $6^{\text {th }}$ edn. St. Louis, CV Mosby Co 1980:976-8.

[3] Becton JL, Christian JD, Goodwin HN, et al. A simplified technique for treating the complex dislocation of index metacarpophalangeal joint. J Bone Joint surg Am 1975;57(5):698-700. 


\section{Jemds.com}

[4] Dutton RO, Meals RA. Complex dorsal dislocation of the thumb metacarpophalangeal joint. Clin Orthop Relat Res 1982;164:160-4.

[5] Azar FS, Canale T, Beaty J. Campbell's operative orthopaedics. 13 th edn. MOSBY Publishers 2016:24953011.

[6] Freiberg A. Management of proximal interphalangeal joint injuries. Can J Plast Surg 2007;15(4):199-203.

[7] Baldwin LW, Miller DL, Lockhart LD, et al. Metacarpophalangeal-joint dislocations of the fingers. J Bone Joint Surg Am 1967;49(8):1587-90.

[8] Milch H. Subluxation of the index metacarpophalangeal joint; case report. J Bone Joint Surg Am 1965;47:522-3.

[9] Murphy AF, Stark HH. Closed dislocation of the metacarpophalangeal joint of the index finger. J Bone Joint Surg Am 1967;49(8):1579- 86.

[10] Dinh P, Franklin A, Hutchinson B, et al. Metacarpophalangeal joint dislocation. J Am Acad Orthop Surg 2009;17(5):318-24.

\section{Original Research Article}

[11] Muthu P, Fraser-Moodie A. Volar metacarpophalangeal joint dislocation. J Accid Emerg Med 2000;19(1):92.

[12] Somani AM, Mahajan UD. Dorsal approach for open reduction of complex metacarpophalangeal joint dislocation: a case report. International J of Healthcare and Biomedical Research 2015;3(3):241-5.

[13] Kc IP, Wong LY, Yu SJ. Dorsal dislocation of the metacarpophalangeal joint of the thumb: a case report. Journal of Orthopaedic Surgery 2008;16(1):124-6.

[14] Green DP, Terry GC. Complex dislocation of the metacarpophalangeal joint. Correlative pathological anatomy. J Bone Joint Surg 1973;55(7):1480-6.

[15] Mihir D, Dhrumin S, Orthopaedics MS. 2 cases of open complex Kaplan's dislocation of thumb and of 2nd to 4th metacarpophalyngeal joint associated with ipsilateral anterior shoulder dislocation; a rare case report. European Journal of Pharmaceutical and Medical Research 2016;3(6):381-6. 